\title{
Physicomechanical characterization of polyetheretherketone and current esthetic dental CAD/CAM polymers after aging in different storage media
}

\author{
Liebermann, Anja ; Wimmer, Timea ; Schmidlin, Patrick R ; Scherer, Harry ; Löffler, Patrick ; Roos, \\ Malgorzata ; Stawarczyk, Bogna
}

\begin{abstract}
STATEMENT OF PROBLEM: Polyetheretherketone (PEEK) can be used to support fixed dental prostheses. However, information about physicomechanical characterization is still scarce. PURPOSE: The purpose of this in vitro study was to assess effects of different aging regimens/durations on roughness, solubility, water absorption, Martens hardness (HM), and indentation modulus/EIT on different computer-aided design and computer-aided manufacturing (CAD/CAM) polymers. MATERIAL AND METHODS: Forty standardized specimens of the following materials were fabricated: PEEK: Dentokeep (DK); hybrid material: VITA Enamic (EN); composite resins: LAVA Ultimate (LU) and an experimental CAD/CAM nanohybrid-composite resin (EX); poly(methyl methacrylate) (PMMA)-based: VITA CAD-Temp (CT); Telio CAD (TC), artBloc Temp (AT), and ZENOTEC ProFix (ZP). A nanofilledpolymer for interim restorations, Protemp $4(\mathrm{CG})$, served as the control group. Specimens were stored in sodium chloride, artificial saliva, physiological saliva, and distilled water at $37^{\circ} \mathrm{C}$ for $1,7,14,28,90$, and 180 days. Roughness, water absorption, HM, and EIT were investigated after each storage period; solubility was determined after 180 days only. Data were analyzed using weighted 3/2/1-way ANOVA and the post hoc Scheffé tests $(=.05)$. RESULTS: Storage media had no effect on surface roughness and water absorption. Physiological saliva revealed the highest significant impact on solubility followed by artificial saliva, sodium chloride, and distilled water. Water absorption increased significantly with storage duration. PEEK showed the lowest solubility and water absorption values. The highest solubility was observed for the conventional polymer CG, and the highest water absorption was found for the composite LU. PMMA-based TC, ZP, CG, and AT showed the lowest HM and indentation modulus, followed by CT, and PEEK. The highest values were observed for the hybrid material EN, followed by LU and EX. CONCLUSIONS: The hardness parameters of PEEK were comparable with those of PMMA-based materials.
\end{abstract}

DOI: https://doi.org/10.1016/j.prosdent.2015.09.004

Posted at the Zurich Open Repository and Archive, University of Zurich

ZORA URL: https://doi.org/10.5167/uzh-123334

Journal Article

Accepted Version

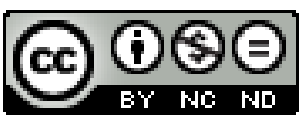

The following work is licensed under a Creative Commons: Attribution-NonCommercial-NoDerivatives 4.0 International (CC BY-NC-ND 4.0) License. 
Originally published at:

Liebermann, Anja; Wimmer, Timea; Schmidlin, Patrick R; Scherer, Harry; Löffler, Patrick; Roos, Malgorzata; Stawarczyk, Bogna (2016). Physicomechanical characterization of polyetheretherketone and current esthetic dental CAD/CAM polymers after aging in different storage media. Journal of Prosthetic Dentistry, 115(3):321-328.

DOI: https://doi.org/10.1016/j.prosdent.2015.09.004 
JPD-15-382

Physicomechanical characterization of polyetheretherketone (PEEK) and current esthetic dental CAD/CAM polymers after aging in different storage media

\begin{abstract}
Statement of problem. Polyetheretherketone (PEEK) can be used to support fixed dental prostheses (FDPs). However, information about the physicomechanical characterization is still scarce.

Purpose. The purpose of this in vitro study was to assess the effect of different aging regimen/durations on roughness, solubility, water absorption, Martens hardness/HM, and indentation modulus/ $\mathrm{E}_{\mathrm{IT}}$ on different computer-aided design and computer-aided manufacturing (CAD/CAM) polymers.
\end{abstract}

Material and methods. Forty standardized specimens of the following materials were fabricated: PEEK: Dentokeep/DK; hybrid material: VITA Enamic/EN; composite resins: LAVA Ultimate/LU and an experimental CAD/CAM nanohybrid-composite resin/EX; PMMA-based: VITA CAD-Temp/CT, Telio CAD/TC, artBloc Temp/AT, and ZENOTEC ProFix/ZP; a nanofilled-polymer for interim restorations: Protemp 4/CG served as the control group. Specimens were stored in sodium chloride, artificial saliva, physiological saliva, and distilled water at $37^{\circ} \mathrm{C}$ for $1,7,14,28,90$, and 180 days. Roughness, water absorption, HM, and $\mathrm{E}_{\mathrm{IT}}$ were investigated after each storage period; solubility was determined after 180 days only. Data were analyzed using weighted 3/2/1-way ANOVA and the posthoc Scheffé tests $(\alpha=05)$.

Results. Storage media had no effect on surface roughness and water absorption. Physiological saliva revealed the highest significant impact on solubility followed by artificial saliva, sodium chloride, and distilled water. Water absorption increased significantly with storage duration. PEEK showed the lowest solubility and water absorption values. The highest 
solubility was observed for the conventional polymer CG, and the highest water absorption was found for the composite LU. PMMA-based TC, ZP, CG, and AT showed the lowest HM and indentation modulus, followed by $\mathrm{CT}$, and PEEK. The highest values were observed for the hybrid material EN, followed by LU and EX.

Conclusions. The hardness parameters of PEEK were comparable with those of PMMAbased materials.

\section{Clinical implications}

With respect to the hardness parameter, PEEK can be recommended as a framework material for FDPs. PEEK is comparable with established PMMA-based materials and displays favorable water absorption and solubility characteristics.

\section{INTRODUCTION}

The restorative and prosthetic materials used in oral rehabilitation are subjected to a complex and changing humid and wet oral environment, which is physiologically characterized by natural saliva and its components. ${ }^{1-3}$ Polymer networks, in particular, tend to absorb water from the surroundings depending on their specific hydrophilicity and on the humidity of the mouth. ${ }^{4,5}$ Potential deleterious effects may arise from $\mathrm{pH}$ changes due to cariogenic biofilms in the oral ecology, diet intake, and different enzymes. ${ }^{6}$ This can lead not only to esthetic problems in terms of water absorption and discoloration but also to the mechanical weakening of the materials and decreased fracture resistance or increased wear. ${ }^{7,8}$

Novel polymers with different matrix compositions and variable percentages of ceramic and resin fillers are available as monolithic materials fabricated by computer-aided design and computer-aided manufacturing (CAD/CAM) techniques. The manufacturers claim that these materials display improved mechanical properties, lower discoloration rates, and higher wear resistance compared with manually polymerized polymers for interim 
restorations due to better manufacturing processes, which encompass high pressures and temperatures leading to better and more constant restoration qualities. ${ }^{9-12}$ Therefore, such novel CAD/CAM polymers may be considered as alternative materials to ceramic fixed dental prostheses (FDPs).

The most frequently used CAD/CAM polymers are PMMA-, composite resin-, or polyetheretherketone (PEEK)-based materials. PEEK shows remarkable mechanical properties ${ }^{13,14}$ and has been evaluated for use for FDPs in load-bearing areas. ${ }^{15-17}$ However, PEEK restorations have a grayish-brown or pearl-white opaque color and need to be veneered with composite resin. Previous studies obtained adequate bond strength to composite resin cements when PEEK surfaces were pretreated and conditioned using adhesive systems contains MMA-monomers. $^{18-25}$

Variations in the composition of CAD/CAM polymers aiming to improve mechanical properties may affect water absorption ${ }^{9,26,27}$ and dimensional change. These alterations can be explained by fluid absorption in the polymer matrix due to molecule polarity, especially within the first few days, leading to an overall imbalance between the intermolecular forces. ${ }^{5,28}$ Martens hardness enables a physicomechanical characterization of the local mechanical properties of materials, including the elastic and plastic parts under different loading regimens. ${ }^{29,30}$ Most of the available studies, however, only determined the reduced mechanical properties of resins after aging in artificial saliva, alcohol, and distilled water. $^{31,32}$ To date, only limited information is available on the long-term behavior of contemporary polymers such as PEEK with regard to different aging regimens. The purpose of this study was to determine the physicomechanical characteristics of PMMA, composite resin, and PEEK after different aging regimens and durations with the following assessment methods: roughness, solubility, water absorption, Martens hardness, and indentation modulus. The null-hypotheses tested were that storage media and storage duration would not affect the roughness, solubility, water absorption, Martens hardness, or indentation modulus of the 
tested polymers. In addition, the aging of PEEK was compared withPMMA and composite resin materials.

\section{MATERIAL AND METHODS}

The investigated materials are summarized in Table 1. From the control group(CG),15 blocks $(15 \times 10 \times 10 \mathrm{~mm})$ were fabricated from a silicone mold and polymerized in a pressure pot (Palamat Elite Polymerization Unit; Heraeus Kulzer) at $450 \mathrm{kPa}$ for 20 minutes. Subsequently, 360 specimens were prepared by cutting the blocks into standardized pieces of $10 \times 10 \times 3 \pm 0.005 \mathrm{~mm}(\mathrm{n}=40 /$ material group) with a diamond saw (Secotom-50; Struers) under water-cooling. The specimens were polished (Tegramin-20; Struers) with a series of silicon carbide papers (SiC) up to P4000 under water-cooling and cleaned in an ultrasonic bath (Ultrasonic T-14; L\&R Manufacturing Co) with distilled water for 5 minutes. Specimens from each group were divided into 5 subgroups $(n=10)$ with different storage media: sodium chloride $(\mathrm{NaCl}$; physiologic salt solution $0.9 \%$; $\mathrm{B}$. Braun; $\mathrm{pH}=5.7)$, artificial saliva $(\mathrm{KCl} 0.4$ $\mathrm{g} / \mathrm{L}, \mathrm{NaCl} 0.4 \mathrm{~g} / \mathrm{L}, \mathrm{CaCl} 2,2 \mathrm{H}_{2} \mathrm{O} 0.906 \mathrm{~g} / \mathrm{L}, \mathrm{NaH}_{2} \mathrm{PO}_{4}, 2 \mathrm{H}_{2} \mathrm{O} 0.690 \mathrm{~g} / \mathrm{L}, \mathrm{Na}_{2} \mathrm{~S}, 9 \mathrm{H}_{2} \mathrm{O} 0.005$ $\mathrm{g} / \mathrm{L}$, and urea $1 \mathrm{~g} / \mathrm{L} ; \mathrm{pH}=4.7$ ), ${ }^{33}$ distilled water (Aqua Bidest.; Kerndl; $\mathrm{pH}=6.7$ ), and natural extracted saliva $(\mathrm{pH}=6.85)$ were used. To represent the diverse bacterial populations, the natural saliva from 10 healthy individuals was collected, and an equal volume of saliva from each of the donors was combined for the experiments. All healthy individuals had natural dentitions without any active caries or clinically diagnosed periodontitis. They had not brushed their teeth in the previous 24 hours and had abstained from food/drink intake at least 2 hours before donating saliva. Stimulated saliva was collected during parafilm chewing and kept on ice. It was stored at $37^{\circ} \mathrm{C}$, and the media were changed every 14 days. The different $\mathrm{pH}$ values were measured on a daily basis (Voltcraft PH-100 ATC; Conrad Electronic). After $1,7,14,28,90$, and 180 days, the roughness, water absorption, Martens hardness, and indentation modulus were measured. Solubility was determined after 180 days. 
The surface roughness measurements were made with a profilometer (MarSurf M400+SD26; Mahr GmbH). To achieve accurate and reproducible results, the specimens were fixed in a holding device to keep the surface parallel to the platform of the machine. The 90-degree measuring sensor had a diamond probe tip (diameter $2 \mu \mathrm{m}$ ). The contact force was held at $0.7 \mathrm{mN}$. Each specimen was measured 6 times with a measuring track of $6 \mathrm{~mm}$ set at a distance of $0.25 \mathrm{~mm}$ between each track ( $3 \times$ vertically $/ 3 \times$ horizontally), and the mean roughness value for each specimen was calculated.

In order to assess the solubility before and after storage, all specimens were stored in a drying chamber (Memmert U30 type with Roth Silica Gel Orange; Carl Roth) at a constant temperature of $37^{\circ} \mathrm{C}$ until a constant weight was reached. The duration of drying to achieve a constant temperature was approximately 2 weeks for all specimens under investigation. The drying values were analyzed using the specimens' weight, which was measured with a highprecision scale (NewClassic MF Model, MS 104S/M01; Mettler Toledo). Solubility values were then analyzed with the following equation using the weight results before and after drying: $\mathrm{S}=\mathrm{m} 1-\mathrm{m} 2 ; \mathrm{m} 1$ : specimen's weight before storage; $\mathrm{m} 2$ : specimen's weight after 180 days of storage.

The water absorption during the entire aging period of 180 days was also analyzed on the basis of the weight differences measured always with the high precision scale. The specimens were stored in the drying chamber and weighed until they reached a constant weight. All specimens were then stored in the respective test media in a scaled chamber (Hera Cell 150; Heraeus) at $37^{\circ} \mathrm{C}$ for storage of $1,7,14,28,90$, and 180 days. On the day of measuring and after cleaning in distilled water for 5 seconds, the specimens were gently wiped with a dry filter paper on both sides and air-dried with oil-free air for 15 seconds before testing. The water absorption was analyzed with the formula: WA=m1-m3;m1: specimen's weight on the specific storage level; m3: specimen's first weight of dried specimens. 
The Martens hardness (HM) and indentation modulus $\left(\mathrm{E}_{\mathrm{IT}}\right)$ were assessed using a universal hardness testing machine (Zwick/Roell ZHU 0.2/Z2.5; Zwick). For this purpose, the diamond indenter pyramid ( $\alpha=136$ degrees) of the hardness testing machine was pressed vertically into the specimen's polished surface with a load of $10 \mathrm{~N}$ for 20 seconds. $^{34}$ The maximum penetration depth was $0.05 \mathrm{~mm}$. The indenter displacement of the definite test frame represented the total amount of the elastic deformation of the surface along with the plastic depth of the impression. ${ }^{30}$ All specimens were tested 3 times, and the values of HM and $\mathrm{E}_{\mathrm{IT}}$ were calculated (TestXpert V12.3 Master; Zwick) with the following equations (DIN EN ISO 14577$)^{35}$ :

$H M=\frac{F}{A_{S}(h)}=\frac{F}{26.43 \times h^{2}} ; H M:$ Martens hardness $\left(\mathrm{N} / \mathrm{mm}^{2}\right) ; F:$ Test force $(\mathrm{N}) ; A_{S}(h):$ Surface area of the indenter at distance $h$ from the tip $\left(\mathrm{mm}^{2}\right)$

and

$E_{I T}=\left(1-v_{S}^{2}\right)\left(\frac{\sqrt[2]{A_{p}\left(h_{c}\right)}}{\sqrt{\pi} S}-\frac{\left(1-v_{i}^{2}\right)}{E_{i}}\right)^{-1} ; E_{I T}:$ indentation modulus, elastic modulus of the indenter (Vickers pyramid); $v_{s}$ : Poisson ratio of the specimen; $v_{i}$ : Poisson ratio of the indenter.

Descriptive statistics were calculated, and the normality of data distribution was tested using the Kolmogorov-Smirnov and Shapiro-Wilk test. The Levene test was used to evaluate the assumption of variances' homogeneity. Data were analyzed using the weighted 3-way ANOVA, followed by the posthoc Scheffé test. In addition, the weighted covariance analysis was conducted for water absorption. For solubility defined as the difference between day 180 and initial values, a 2-way weighted ANOVA and two 1-way weighted ANOVAs followed by the posthoc Scheffé test with respect to the 2 factors of material and storage medium were considered. The statistical analyses were performed using a statistical program (SPSS v20; IBM Corp) $(\alpha=.05)$. 


\section{RESULTS}

The Kolmogorov-Smirnov and Shapiro-Wilk tests indicated the highest rate (79 \%) of violations of the normality assumption for surface roughness. The corresponding percentages for solubility, water absorption, Martens hardness, and indentation modulus were equal to $25 \%, 11 \%, 27 \%$, and $16 \%$. The violation of the normality assumption was not caused by outliers but rather by measurement rounding, leading to an increased coarseness of the observations in each test group. Additionally, the Levene tests for all dependent variables indicated violation of the variance homogeneity assumption $(P<.001)$. The reasons for the increased spread were differences in the dependent variables: surface roughness (EX) solubility (TC, AT, CG), water absorption (ZP), Martens hardness (EN, LU, EX), and indentation modulus (EN, LU, EX). Consequently, weighted statistical analyses had to be considered for all dependent variables.

According to the 3-way ANOVA, the 3-way interaction $(P<.001)$ of materials, storage duration, and storage media for surface roughness was significant. It originated mainly in EX showing lower and in AT showing higher initial roughness in distilled water; ZP presented higher roughness for artificial and physiological saliva at day 90. The 2-way interaction between materials and storage duration $(P<.001)$ originated mainly in EX having initially higher surface roughness. As far as interaction between materials and storage medium $(P<.001)$ was concerned, LU stored in physiological saliva showed the highest roughness. For storage duration and storage media $(P<.001)$ artificial and physiological saliva showed higher roughness at day 90 than both the other media. In addition, the tested materials $(P<.001)$ and the storage duration $(P<.001)$ affected the roughness results (Fig. 1). In contrast, the storage medium $(P=.005)$ had no effect on the surface roughness. In general, the lowest surface roughness was observed for the PMMA-based groups TC and ZP, whereas the highest values were found in the EX group $(P<.001)$ (Fig. 1). With regard to storage duration, higher surface 
roughness was observed at the beginning of the experiment and after 180 days, followed by 90 days of storage and a storage duration of between 1 and 28 days $(P<.001)$.

The 2-way ANOVA interaction for solubility was significant $(P<.001)$. This interaction originated in the CG and CT and showed lower solubility for artificial and physiological saliva than for $\mathrm{NaCl}$ and distilled water in contrast with $\mathrm{DK}, \mathrm{EN}$, and $\mathrm{EX}$, which showed practically unchanged solubility independent of the storage medium (Fig. 2). In general, physiological saliva followed by artificial saliva affected the solubility results more than storage in $\mathrm{NaCl}$. Distilled water had the lowest impact on solubility. PEEK (DK) showed the lowest solubility, whereas the highest solubility was observed for the conventional polymer group for temporary restorations (CG). Specimens stored in physiological saliva showed no differences. Significant differences are shown in Table 2.

The 3-wayANOVA for water absorption found a significant 3-way interaction $(P<.001)$ among materials, storage duration, and storage media. It originated mainly in the CG showing different progress for $\mathrm{NaCl}$ for 1 and 7 days. The 2-way interaction between materials and storage medium $(P<.001)$ was significant, but we were unable to detect its main cause. As far as the interaction between materials and storage duration $(P<.001)$ was concerned, the CG showed higher water absorption at day 7. For storage duration and storage media $(P<.001)$ the interaction at 90 days in distilled water showed lower water absorption. As far as main effects are concerned, the storage medium had no effect on the water absorption results $(P<.001)$. However, significant effects of material $(P<.001)$ and storage level $(P<.001)$ were observed. Therefore, the storage medium groups were pooled, and the results were presented in box-plots with respect to material types and storage media (Fig. 3). In general, the increase of storage time significantly increased the water absorption values $(P<.001)$. PEEK $(\mathrm{DK})$ presented the lowest water absorption rates $(P<.001)$. The highest values were observed for the composite resin material LU. In addition, the weighted analysis of covariance indicated a significant interaction term between storage duration and material. 
Water absorption increase was steeper $(P<.001)$ for EN, LU, EX, CT, TC, and AT than for the CG. No difference in the slope of the water absorption for DK and CG with respect to storage duration was found $(P=.999)$.

The 3-way interaction for Martens hardness among the materials, storage duration and storage media was found with the 3-way ANOVA $(P<.001)$. It originated mainly in EN showing lower HM for artificial saliva at day 90 than at day 180, which contrasted with other materials and storage media. As far as interaction between materials and storage medium $(P<.001)$ was concerned, LU showed elevated $\mathrm{HM}$ for $\mathrm{NaCl}$ and artificial saliva than $\mathrm{EN}$. The 2-way interaction between materials and storage duration $(P<.001)$ originated mainly in EN having a differing progress of HM than LU and EX and the rest of the materials. Interaction for storage duration and storage media $(P<.001)$ could not be easily interpreted as it appeared to be marginalized with respect to the material. In principle, the groups stored for 90 and 180 days showed lower HM than the non-aged groups $(P<.001)$. With respect to the aging media, the specimens stored in artificial saliva presented the lowest HM as compared with specimens aged in distilled water or physiological saliva $(P<.001)$. Storage in $\mathrm{NaCl}$ produced lower $\mathrm{HM}$ than storage in physiological saliva $(P<.001)$. The PMMA-based materials $(\mathrm{TC}, \mathrm{ZP}, \mathrm{CG}$, and AT) showed the lowest HM, followed by CT and PEEK DK $(P<.001)$. The highest values were observed for the hybrid material EN, followed by the composites LU and $\mathrm{EX}(P<.001)$ (Supplementary Fig. 1).

Interpretations of the 3-way interaction $(P<.001)$ and the2-way interactions $(P<.001)$ for indentation modulus was similar to those discussed for HM. According to the 3-way ANOVA, material $(P<.001)$ and aging medium $(P<.001)$ affected $\mathrm{E}_{\mathrm{IT}}$. The aging level, however, had no effect on $\mathrm{E}_{\mathrm{IT}}(\mathrm{P}=.155)$. The influence of the material (Fig. 5) and the aging medium was similar to the HM results (Table 3). 


\section{DISCUSSION}

The highest impact on solubility was found for storage in physiological saliva, followed by artificial saliva, $\mathrm{NaCl}$, and distilled water. This outcome indicates that natural saliva contains components that lead to a higher solubility rate than artificial saliva and especially $\mathrm{NaCl}$ and distilled water. Physiological saliva is composed of a complex mixture of secretory organic and inorganic products, whereas water contained $99 \%$ in contrast with pure distilled water (100\%) with the lowest impact on solubility. All organic and inorganic molecules and solid components are dissolved in the aqueous component and can be different from one person to another and even from one person at different times during the day. ${ }^{2,3}$ This might have led to the diverse results in the present study when the extraction of saliva differed minimally in time or composition. In addition to the inorganic part of weak and strong ions $\left(\mathrm{Na}^{+}, \mathrm{K}^{+}\right.$, and $\mathrm{Cl}^{-}$, for example), natural saliva consists of organic parts, including urea and more than 400 types of protein. ${ }^{2,3}$ These proteins vary in artificial saliva and possibly reflect the differing results and the higher solubility of natural saliva. To date, little is known about the behavior of the tested materials when stored in artificial and particularly in physiological saliva. Only AT showed no solubility after 180 days of physiological saliva storage. The remaining materials exhibited significant solubility, regardless of the storage media. The lowest material loss was observed for PEEK (DK), the highest for the CG.

The water absorption results were independent of the storage medium. Material and storage duration had significant effects on water absorption. Unsurprisingly, longer storage times resulted in increased water absorption rates, which is corroborated by the composite resin results from a previous study. ${ }^{4}$ However, in the case of distilled water and even artificial saliva, water absorption was dependent on storage time and material. ${ }^{4}$ Our results support the concept that water absorption generally increases with higher amounts of resin matrix and a lower amount of filler particles. Since the latter cannot absorb water, higher matrix proportions can lead to filler-matrix debonding or even hydrolytic degradation. ${ }^{4,5,32}$ In 
addition, the more homogeneous a polymer is, the less water is absorbed and the less soluble characteristics it has. ${ }^{12}$ As confirmed in this study, industrially fabricated CAD/CAM materials show a reduced risk of porosities and therefore higher and more solid mechanical properties. ${ }^{16}$ Another study reported negative effects on surface properties when microhybrid composite resin was stored in saliva, alcohol, and bacterial acid. However, the $\mathrm{pH}$ changes seemed not to intensify surface degradation. ${ }^{5,32}$ Bacterial contamination in the physiological saliva may also have contributed to additional degradation of the tested specimens. The saliva was not filtered or sterilized to mimic the clinical situation. Furthermore, water absorption and release can cause molecular instabilities, which may lead to crack formations and a decrease in mechanical properties as already mentioned. ${ }^{28}$ Water absorption not only affects physical and mechanical properties, especially of composite resins but also decreases surface hardness and the elastic modulus, ${ }^{4}$ particularly as reflected in this study.

This study showed that specimens stored in artificial saliva resulted had lower HM values than specimens aged in distilled water or physiological saliva. In general, non- or lowfilled materials (PMMA and PEEK) showed the lowest HM, whereas the highest values were found for materials with high percentages of filler particles, such as VITA Enamic, LAVA Ultimate, and the experimental nanohybrid-composite resin (with a filler content of $80 \%$ ). Therefore, the null hypothesis that storage media and storage duration have no effect on the roughness, solubility, water absorption, $\mathrm{HM}$, and $\mathrm{E}_{\mathrm{IT}}$ of the tested polymers is rejected.

The most obvious changes in the mechanical and physical properties of polymers can be expected within the first 30 days of testing based on the results of previous studies with a comparable study design. ${ }^{36,37}$ Therefore, 4 aging levels in this first month $(1,7,14$, and 28 days) showed assessing distinct hardness changes. Two more measurements after 90 and 180 days were made when more stable values were again expected. Temperature changes to imitate the natural oral environment while drinking and eating were made in distilled water in a thermocycler, which, because of the vaporization process, required a large volume of liquid. 
The present study used different media, where physiological saliva especially was difficult to acquire in large volume. For a meaningful comparison of all media, storage in an incubator at a constant temperature of $37^{\circ} \mathrm{C}$ (clinical mouth temperature) was chosen. Further studies analyzing mechanical parameters at different temperatures would be interesting. Laboratory tests provide only some evidence of reliable values. Clinical studies must be performed to validate the obtained results.

One limitation of this study was the lack of power analysis in its planning stage. When choosing 10 observations, we relied to some extent on the experience of a previous study also based on 10 observations. ${ }^{37}$ However, a posthoc power analysis to justify the chosen sample size at least partly was conducted. Given the observed pooled standard deviation of solubility (0.4 mg), the 2-sided 2-sample $t$ test has a power of $98 \%$ to detect a difference of $0.75 \mathrm{mg}$ ( $50 \%$ of the pooled effect in CG). Note that the observed difference of $1.2 \mathrm{mg}$ between the pooled means in DK and CG is larger and corresponds to an $80 \%$ decrease insolubility with respect to the $\mathrm{CG}$.

\section{CONCLUSION}

Within the limitations of this in vitro study, it can be concluded that the hardness parameters of PEEK were comparable with those of established PMMA-based materials and that PEEK shows low solubility and water absorption rates. Therefore, PEEK can be recommended for long-term restorations. 


\section{REFERENCES}

1.Ferracane JL, Berge HX, Condon JR. In vitro aging of dental composites in water-effect of degree of conversion, filler volume, and filler/matrix coupling. J Biomed Mater Res 1998;42:465-72.

2.Hofman LF. Human saliva as a diagnostic specimen. J Nutrition 2001;131:1621s-5s.

3.Lima DP, Diniz DG, Moimaz SAS, Sumida DH, Okamoto AC. Saliva: reflection of the body. Int J Infect Dis 2010;14:e184-8.

4.Musanje L, Darvell BW. Aspects of water sorption from the air, water and artificial saliva in resin composite restorative materials. Dent Mater 2003;19:414-22.

5.Munchow EA, Ferreira AC, Machado RM, Ramos TS, Rodrigues-Junior SA, Zanchi CH. Effect of acidic solutions on the surface degradation of a micro-hybrid composite resin. Braz Dent J 2014;25:321-6.

6.Turssi CP, Hara AT, de Magalhaes CS, Serra MC, Rodrigues AL, Jr. Influence of storage regime prior to abrasion on surface topography of restorative materials. J Biomed Mater Res B Appl Biomater 2003;65:227-32.

7.Ferracane JL. Is the wear of dental composites still a clinical concern? Is there still a need for in vitro wear simulating devices? Dent Mater 2006;22:689-92.

8.Lohbauer U, Belli R, Ferracane JL. Factors involved in mechanical fatigue degradation of dental resin composites. J Dent Res 2013;92:584-91.

9.Stawarczyk B, Ender A, Trottmann A, Özcan M, Fischer J, Hämmerle CH. Load-bearing capacity of $\mathrm{CAD} / \mathrm{CAM}$ milled polymeric three-unit fixed dental prostheses: effect of aging regimens. Clin Oral Investig 2012;16:1669-77.

10.Stawarczyk B, Özcan M, Trottmann A, Schmutz F, Roos M, Hämmerle C. Two-body wear rate of CAD/CAM resin blocks and their enamel antagonists. J Prosthet Dent 2013;109:32532. 
11.Stawarczyk B, Sener B, Trottmann A, Roos M, Ozcan M, Hammerle CH. Discoloration of manually fabricated resins and industrially fabricated CAD/CAM blocks versus glassceramic: effect of storage media, duration, and subsequent polishing. Dent Mater J 2012;31:377-83.

12.Czasch P, Ilie N. In vitro comparison of mechanical properties and degree of cure of bulk fill composites. Clin Oral Investig 2013;17:227-35.

13.Kurtz SM, Devine JN. PEEK biomaterials in trauma, orthopedic, and spinal implants. Biomaterials 2007;28:4845-69.

14.Toth JM, Wang M, Estes BT, Scifert JL, Seim HB, 3rd, Turner AS. Polyetheretherketone as a biomaterial for spinal applications. Biomaterials 2006;27:324-34.

15.Stawarczyk B, Beuer F, Wimmer T, Jahn D, Sener B, Roos M, et al. Polyetheretherketonea suitable material for fixed dental prostheses? J Biomed Mater Res B Appl Biomater 2013;101:1209-16.

16.Stawarczyk B, Eichberger M, Uhrenbacher J, Wimmer T, Edelhoff D, Schmidlin PR. Three-unit reinforced polyetheretherketone composite FDPs: Influence of fabrication method on load-bearing capacity and failure types. Dent Mater J 2015;34:7-12.

17.Stawarczyk B, Thrun H, Eichberger M, Roos M, Edelhoff D, Schweiger J, Schmidlin PR. Effect of different surface pretreatments and adhesives on the load-bearing capacity of veneered 3-unit PEEK FDPs. J Prosthet Dent 2015; in press

18.Uhrenbacher J, Schmidlin PR, Keul C, Eichberger M, Roos M, Gernet W, Stawarczyk B. The effect of surface modification on the retention strength of polyetheretherketone crowns adhesively bonded to dentin abutments. J Prosthet Dent 2014;112:1489-97.

19.Sproesser O, Schmidlin PR, Uhrenbacher J, Roos M, Gernet W, Stawarczyk B. Effect of sulfuric acid etching of polyetheretherketone on the shear bond strength to resin cements. $\mathrm{J}$ Adhes Dent 2014;16:465-72. 
20.Keul C, Liebermann A, Schmidlin PR, Roos M, Sener B, Stawarczyk B. Influence of PEEK surface modification on surface properties and bond strength to veneering resin composites. J Adhes Dent 2014;16:383-92.

21.Stawarczyk B, Bähr N, Beuer F, Wimmer T, Eichberger M, Gernet W, et al. Influence of plasma pretreatment on shear bond strength of self-adhesive resin cements to polyetheretherketone. Clin Oral Investig 2014;18:163-70.

22.Stawarczyk B, Jordan P, Schmidlin PR, Roos M, Eichberger M, Gernet W, et al. PEEK surface treatment effects on tensile bond strength to veneering resins. J Prosthet Dent $2014 ; 112: 1278-88$

23.Schmidlin PR, Stawarczyk B, Wieland M, Attin T, Hämmerle CH, Fischer J. Effect of different surface pre-treatments and luting materials on shear bond strength to PEEK. Dent Mater 2010;26:553-9.

24.Stawarczyk B, Keul C, Beuer F, Roos M, Schmidlin PR. Tensile bond strength of veneering resins to PEEK: impact of different adhesives. Dent Mater J 2013;32:441-8. 25.Sproesser O, Schmidlin PR, Uhrenbacher J, Eichberger M, Roos M, Stawarczyk B. Work of adhesion between resin composite cement and PEEK as a function of etching duration with sulfuric acid and its correlation with bond strength values. Int J Adhes Adhes 2014;54:184-90. 26.Alix S, Colasse L, Morvan C, Lebrun L, Marais S. Pressure impact of autoclave treatment on water sorption and pectin composition of flax cellulosic-fibres. Carbohydr Polym 2014;102:21-9.

27.Gusmao GM, De Queiroz TV, Pompeu GF, Menezes Filho PF, da Silva CH. The influence of storage time and $\mathrm{pH}$ variation on water sorption by different composite resins. Indian $\mathrm{J}$ Dent Res 2013;24:60-5.

28.Tuna SH, Keyf F, Gumus HO, Uzun C. The evaluation of water sorption/solubility on various acrylic resins. Eur J Dent 2008;2:191-7. 
29.Moosavi H, Hariri I, Sadr A, Thitthaweerat S, Tagami J. Effects of curing mode and moisture on nanoindentation mechanical properties and bonding of a self-adhesive resin cement to pulp chamber floor. Dent Mater 2013;29:708-17.

30.Shahdad SA, McCabe JF, Bull S, Rusby S, Wassell RW. Hardness measured with traditional Vickers and Martens hardness methods. Dent Mater 2007;23:1079-85.

31.Mayworm CD, Camargo SS, Jr., Bastian FL. Influence of artificial saliva on abrasive wear and microhardness of dental composites filled with nanoparticles. J Dent 2008;36:703-10. 32.Ferracane JL. Hygroscopic and hydrolytic effects in dental polymer networks. Dent Mater 2006;22:211-22.

33.Meyer JM, Wirthner JM, Barraud R, Susz CP, Nally JN. Corrosion studies on nickel-based casing alloys. Corrosion and degradation of implant materials, ed. B. C. Syrett and A. Acharya. ASTM STP 684. American Society for Testing and Materials 1979:295-315. 34.Menne-Happ U, Ilie N. Effect of gloss and heat on the mechanical behaviour of a glass carbomer cement. J Dent 2013;41:223-30.

35.114577 ID. Metallic materials - Instrumented indentation test for hardness and materials parameters - Part 1: Test method (ISO/DIS 14577-1:2012); German version prEN ISO1:2012. 2012.

36.Fischer J, Roeske S, Stawarczyk B, Hämmerle CH. Investigations in the correlation between Martens hardness and flexural strength of composite resin restorative materials. Dent Mater J 2010;29:188-92.

37.Stawarczyk B, Egli R, Roos M, Özcan M, Hämmerle CH. The impact of in vitro aging on the mechanical and optical properties of indirect veneering composite resins. J Prosthet Dent 2011;106:386-98. 
Table 1. Summary of materials, abbreviations, compositions, manufacturers, and Lot numbers

\begin{tabular}{|c|c|c|c|c|c|}
\hline $\begin{array}{l}\text { Material } \\
\text { group }\end{array}$ & $\begin{array}{l}\text { CAD/CAM } \\
\text { materials }\end{array}$ & $\begin{array}{l}\text { Abbreviatio } \\
\mathrm{n}\end{array}$ & Composition & $\begin{array}{l}\text { Manufacture } \\
\mathrm{r}\end{array}$ & Lot No. \\
\hline $\begin{array}{l}\text { CAD/CAM } \\
\text { PEEK for } \\
\text { definitive } \\
\text { restorations }\end{array}$ & Dentokeep & DK & $\begin{array}{l}\text { Ceramic filled } \\
(20 \%) \\
\text { polyetheretherketon } \\
\text { e (PEEK) }\end{array}$ & nt-trading & $\begin{array}{l}\text { 11DK } 1400 \\
1\end{array}$ \\
\hline $\begin{array}{l}\text { CAD/CAM } \\
\text { Hybrid } \\
\text { material for } \\
\text { definitive } \\
\text { restorations }\end{array}$ & $\begin{array}{l}\text { VITA } \\
\text { Enamic }\end{array}$ & EN & $\begin{array}{l}\text { Ceramic: } 86 \% \\
\mathrm{SiO}_{2}: \\
\mathrm{Al}_{2} \mathrm{O}_{3}: \quad 58-63 \%, \\
\mathrm{Na}_{2} \mathrm{O}: 6-11 \%, \mathrm{~K}_{2} \mathrm{O}: \\
4-6 \%, \quad \mathrm{~B}_{2} \mathrm{O}_{3}: \quad 0.5- \\
2 \%, \quad \mathrm{ZrO}_{2}, \mathrm{CaO}: \\
<1 \% \\
\text { Polymer: } \quad 14 \% \\
\text { UDMA+TEGDMA }\end{array}$ & $\begin{array}{l}\text { VITA } \\
\text { Zahnfabrik }\end{array}$ & 34580 \\
\hline $\begin{array}{l}\text { CAD/CAM } \\
\text { nanohybrid- } \\
\text { composites } \\
\text { for } \\
\text { definitive } \\
\text { restorations }\end{array}$ & $\begin{array}{l}\text { LAVA } \\
\text { Ultimate }\end{array}$ & LU & $\begin{array}{l}\text { nanoceramic } \\
\text { components } \\
\text { embedded in highly } \\
\text { cross-linked } \\
\text { polymeric matrix }\end{array}$ & 3M ESPE & N392139 \\
\hline
\end{tabular}




\begin{tabular}{|c|c|c|c|c|c|}
\hline & $\begin{array}{l}\text { exp. } \\
\text { CAD/CAM } \\
\text { nanohybrid- } \\
\text { composite }\end{array}$ & EX & $\begin{array}{l}\text { nanohybrid- } \\
\text { compositeresinwith } \\
\text { additives } \\
\text { filler: } 80 \mathrm{wt} \%\end{array}$ & $\begin{array}{l}\text { Ivoclar } \\
\text { Vivadent }\end{array}$ & b. 28923 \\
\hline \multirow{4}{*}{$\begin{array}{l}\text { CAD/CAM } \\
\text { PMMA- } \\
\text { based } \\
\text { materials for } \\
\text { temporary } \\
\text { restorations }\end{array}$} & $\begin{array}{l}\text { VITA } \\
\text { CAD-Temp }\end{array}$ & $\mathrm{CT}$ & PMMA microfilled & $\begin{array}{l}\text { VITA } \\
\text { Zahnfabrik }\end{array}$ & 11000 \\
\hline & Telio CAD & $\mathrm{TC}$ & $\begin{array}{ll}99.5 \% & \text { PMMA } \\
\text { polymer } & \end{array}$ & $\begin{array}{l}\text { Ivoclar } \\
\text { Vivadent }\end{array}$ & R36500 \\
\hline & $\begin{array}{l}\text { artBlocTem } \\
\mathrm{p}\end{array}$ & AT & $\begin{array}{l}\text { PMMA, } \\
\text { OMP }=\text { organic } \\
\text { modified polymer } \\
\text { network }\end{array}$ & Merz Dental & 23408 \\
\hline & $\begin{array}{l}\text { Zenotec Pro } \\
\text { Fix }\end{array}$ & $\mathrm{ZP}$ & PMMA unfilled & $\begin{array}{l}\text { Wieland } \\
\text { Dental }\end{array}$ & 0801 \\
\hline $\begin{array}{l}\text { Conventiona } \\
1 \text { polymer } \\
\text { for } \\
\text { temporary } \\
\text { restorations }\end{array}$ & Protemp 4 & CG & $\begin{array}{l}\text { Bis-acrylate } \\
\text { composite with } \\
\text { nanofillers }\end{array}$ & 3M ESPE & 487558 \\
\hline
\end{tabular}


Table 2. Descriptive statistics of all solubility values after 180 days storage in different media for each material separately (Difference between 0 and 180 days in $\mathrm{mg}$ )

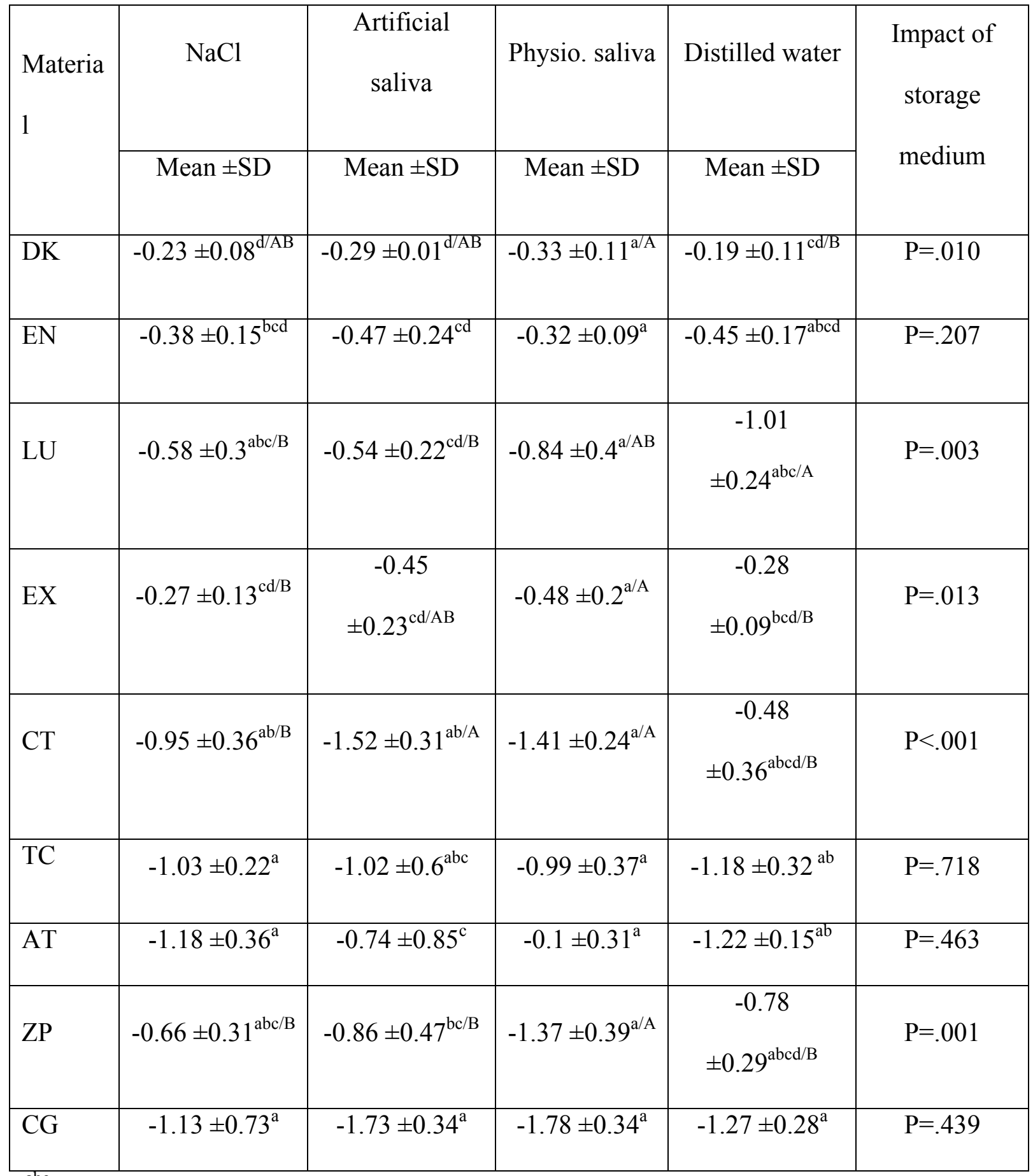

${ }^{a b c}$ Different letters represent significant differences between CAD/CAM materials within one storage medium.

${ }^{A B C}$ Different letters represent significant differences between storage media within one $\mathrm{CAD} / \mathrm{CAM}$ material. 
Figure 1. Roughness values with pooled storage media results divided into each material and storage day. Error bars represent standard deviation.

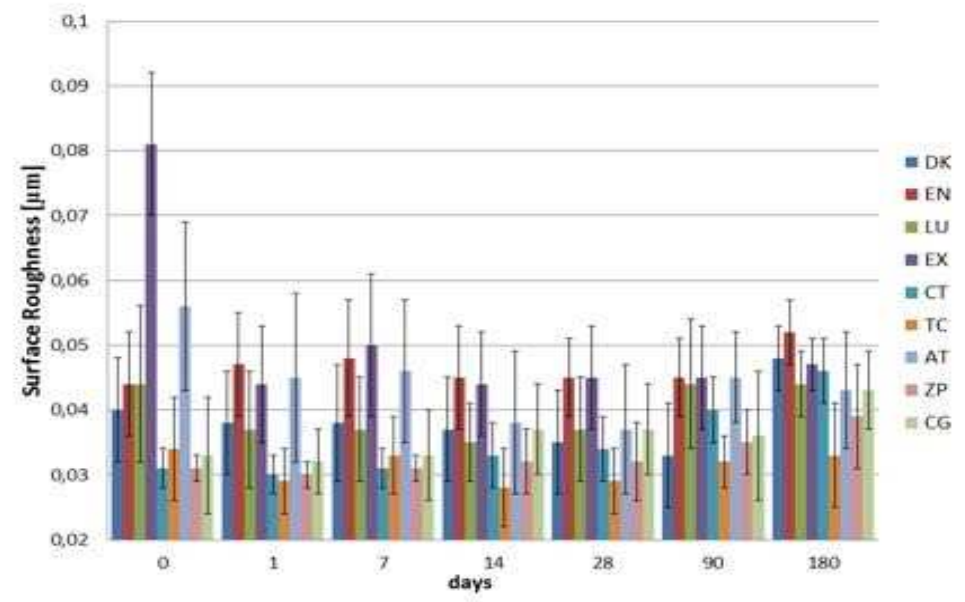

Figure 2. Solubility rates [in $\mathrm{mg}$ ] differences between initial and after 180 days storage of different materials after immersion in different storage media . Limits of whiskers in boxplots are defined as $10^{\text {th }}$ and $90^{\text {th }}$ percentiles.

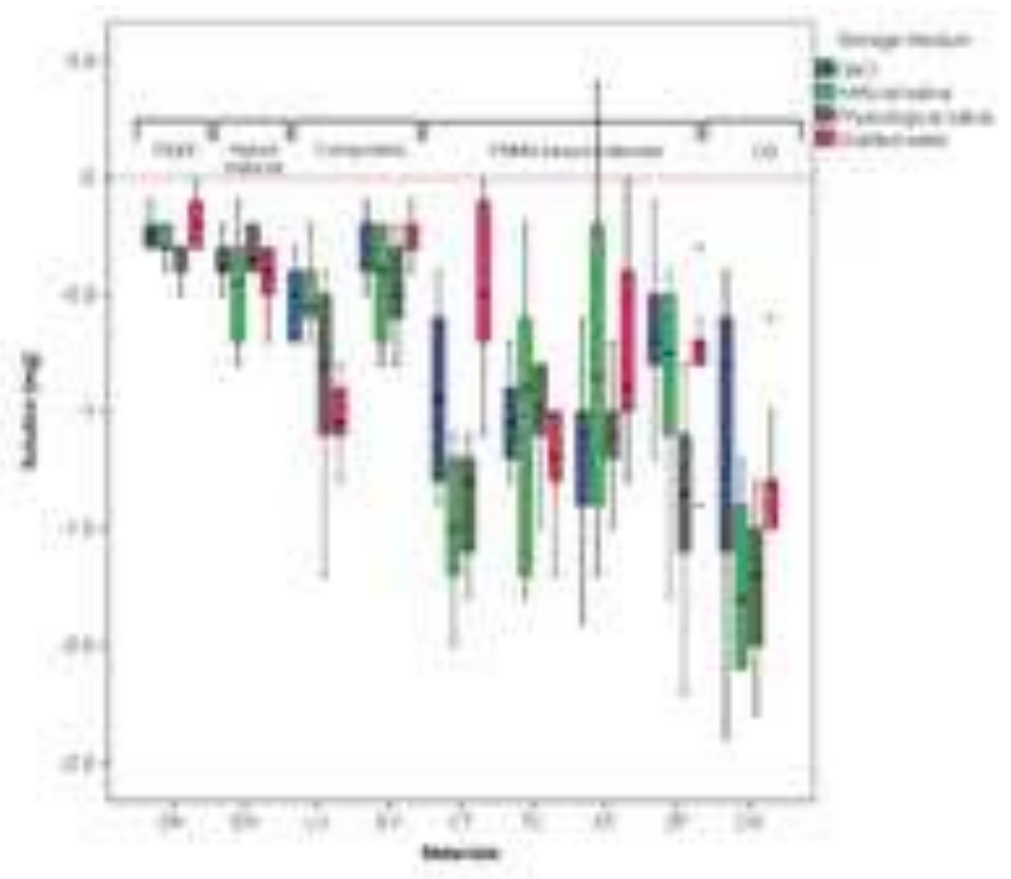


Figure 3. Scatterplot for water absorption values with pooled storage media results.

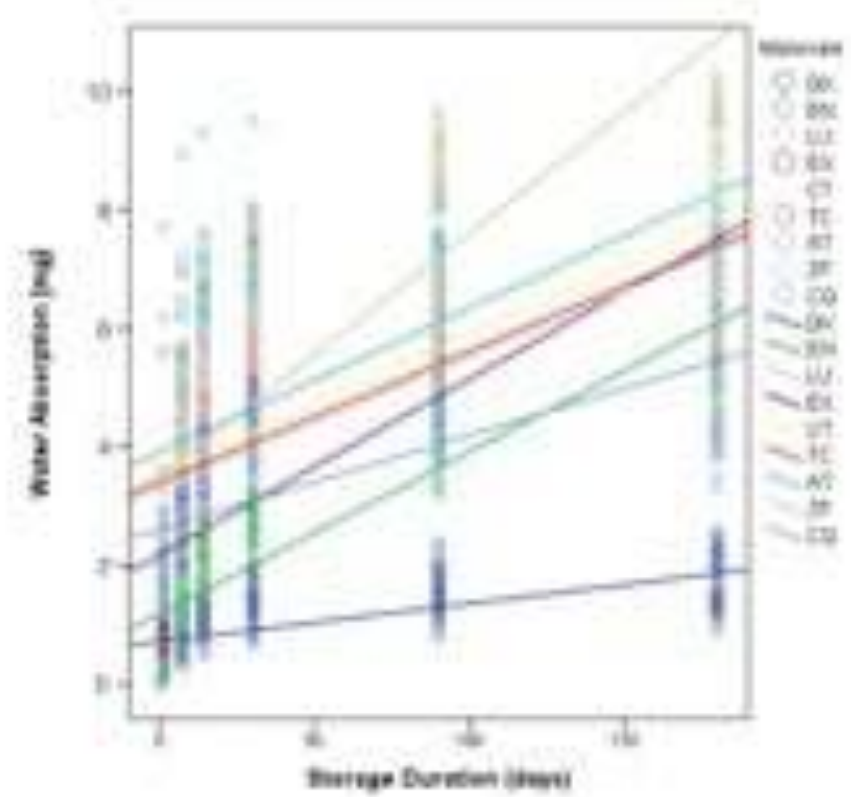

Figure 4. Pooled Martens hardness values for each material separately.Error bars represent standard deviation.

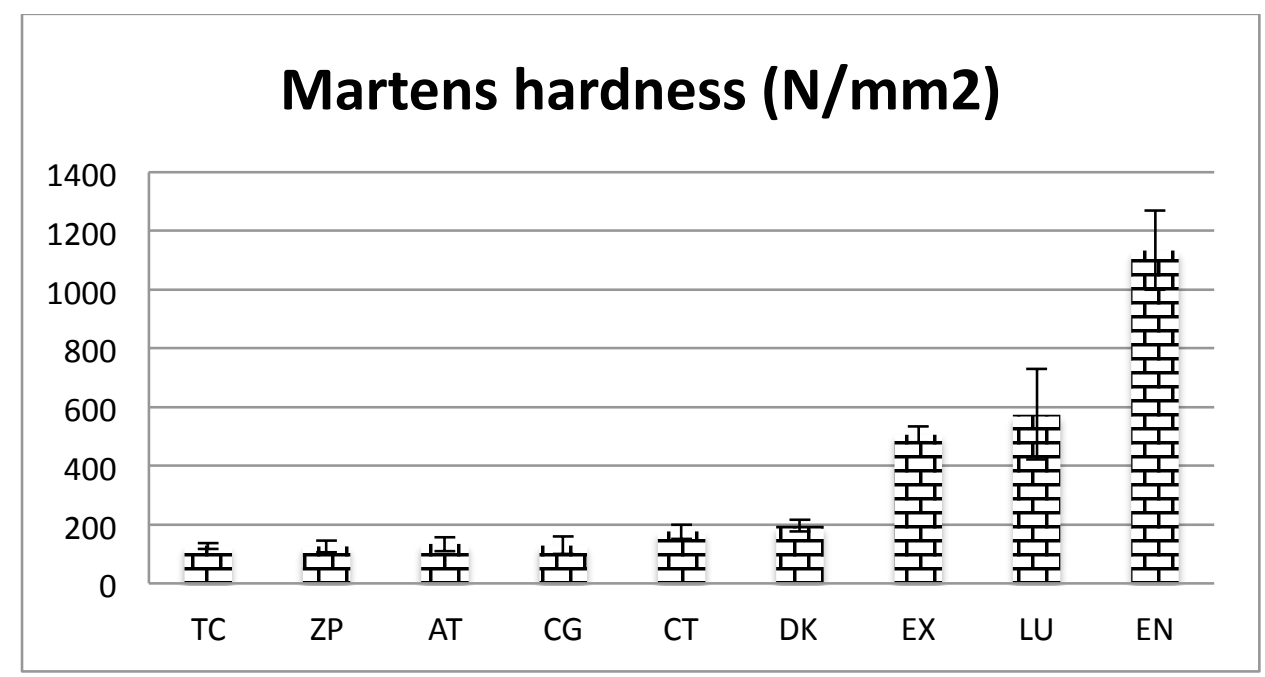


Figure 5. Pooled indentation modulus values for each material separately.Error bars represent standard deviation.

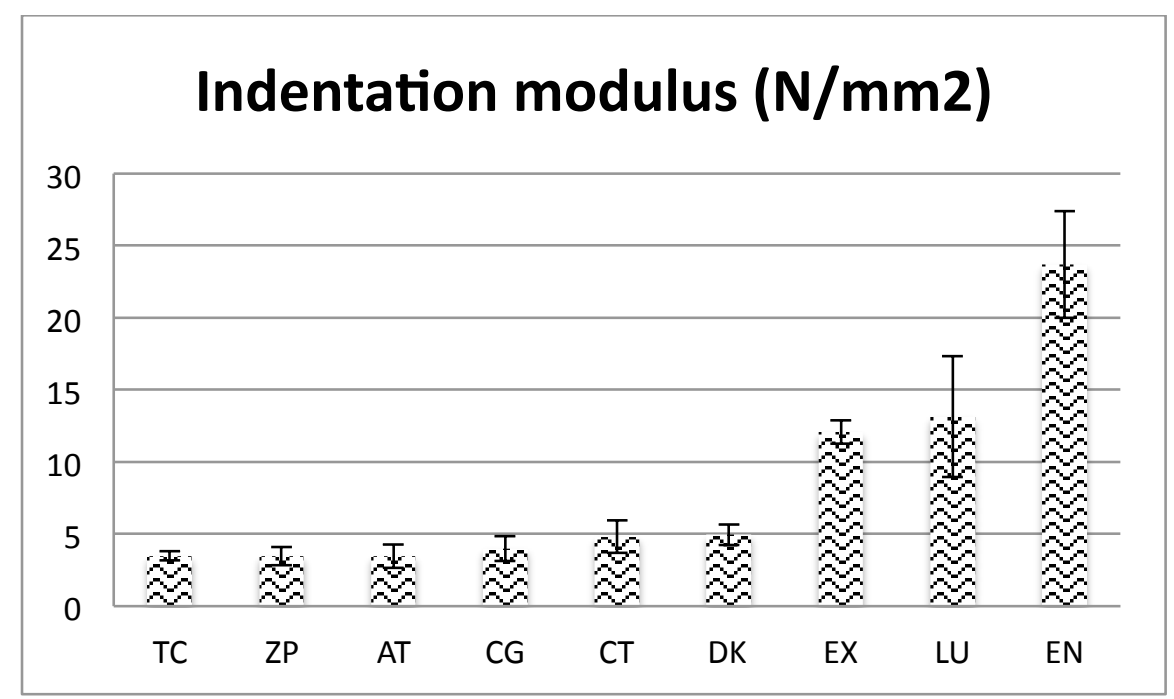

